\title{
La pia Hypermestra y el impius Aeneas: la deconstrucción de Eneas en las Heroidas de Ovidio (Her. XIV; Aen. VI 687-688, 697-698, 700-701)*
}

\author{
Alba Blázquez Noya \\ Universidad de Salamanca \\ albablazqueznoya@gmail.com \\ ORCID iD: https://orcid.org/0000-0002-8058-3773
}

\begin{abstract}
Pia Hypermestra and Impius Aeneas: The Deconstruction of Aeneas in Ovid's Heroides (Her. XIV; Aen. VI 687-688, 697-698, 700-701)
\end{abstract}

En el presente artículo se plantea la hipótesis de que Ovidio deconstruye a Eneas en la Carta de Hipermestra a Linceo (Her. XIV), desmantelando valores culturales hegemónicos ensalzados en la Eneida, como la pietas masculina, mediante la colocación de la pietas conyugal encarnada en Hipermestra como valor central en las Heroidas. A partir del análisis de la relación intertextual entre Her. XIV 45-50 y Aen. 678 ss., se comprueba que existe una relación irónica de contraste entre Hipermestra y Eneas, representantes de ambos tipos de pietas. Se constata que esta relación pretende situar a Eneas en el margen, dado que en las Heroidas el impius Eneas constituye el retrato central del héroe, como se observa en la Carta de Dido a Eneas. Asimismo, se sostiene que Ovidio elige precisamente a Hipermestra como contrapunto femenino del héroe
This paper proposes the hypothesis that Ovid deconstructs Aeneas in the Letter of Hypermestra to Lynceus (Her. XIV) and dismantles hegemonic cultural values extolled in the Aeneid, such as male pietas, by placing conjugal pietas, incarnated in Hipermestra, as a central value in the Heroides. On the basis of the analysis of the intertextual relationship between Her. XIV 45-50 and Aen. 678 ff., it is confirmed that there is an ironic relationship of contrast between Hipermestra and Aeneas, who are representative of both types of pietas. It is verified that this relationship aims to place Aeneas in the margin, since in the Heroides the impius Aeneas constitutes the central portrait of the hero, as can be observed in Dido's Letter to Aeneas. Likewise, it is argued that Ovid choses precisely Hypermestra as the hero's feminine counterpoint because an in-

* Este artículo desarrolla y fundamenta una idea planteada en la tesis doctoral "Intersección de géneros y voces en las Heroidas de Ovidio. Heroínas intertextuales: de la tragedia griega a la epístola ovidiana", por Alba Blázquez Noya, dirigida por Rosario Cortés Tovar, Universidad de Salamanca, 2019.

Agradecemos a los revisores y al Consejo de Redacción su tiempo y sus comentarios, que han servido para completar el presente artículo y matizar distintos aspectos del mismo.

Copyright: (C) 2021 CSIC. Este es un artículo de acceso abierto distribuido bajo los términos de la licencia de uso y distribución Creative Commons Reconocimiento 4.0 Internacional (CC BY 4.0). 
porque en la Eneida se infiere una relación indirecta de oposición entre Eneas e Hipermestra.

Palabras clave: Hipermestra; Eneas; pietas; Heroidas; intertextualidad. direct opposition relationship between Aeneas and Hypermestra can be inferred in the Aeneid.

Key words: Hypermestra; Aeneas; pietas; Heroides; intertextuality.

Cómo citar este artículo / Citation: Blázquez Noya, Alba (2021): «La pia Hypermestra y el impius Aeneas: la deconstrucción de Eneas en las Heroidas de Ovidio (Her. XIV; Aen. VI 687-688, 697-698, 700-701)», Emerita 89 (1), pp. 49-72.

Dentro de la colección de las Heroidas de Ovidio hay una escritora que destaca entre todas las demás como la heroína piadosa por excelencia: Hipermestra (Her. XIV), la única de las Danaides que desobedece la orden de su padre y perdona la vida a su marido Linceo en la noche de bodas, siendo castigada por ello con la prisión ${ }^{1}$. El hecho de que Ovidio configure su Hipermestra como una heroína pia resulta significativo por dos razones. La primera es que esta caracterización es resultado de una innovación ovidiana: tras un análisis de las fuentes griegas y latinas, se concluye que Hipermestra no había sido vinculada anteriormente a la pietas como virtud (Blázquez Noya). La segunda razón es que no hay ninguna otra escritora de la colección que se retrate y se defina destacadamente como heroína piadosa: a lo largo de la carta Hipermestra insiste repetidamente en resaltar su propia pietas y su cualidad de pia por haber perdonado la vida a su marido (Her. XIV 4, 13-14, 49-50, 63-64, 84-83, 123, 129-130); a lo anterior se suma que en la Heroida XIV las palabras pietas o pia aparecen siete veces en 132 versos, lo cual, como apunta Jacobson 1974, pp. 125-126, contrasta con el hecho de que en ninguna otra Heroida aparecen dichas palabras más de tres veces. Como otro argumento más para sostener el especial carácter de pia de la heroína dentro de la colección, se añade que Hipermestra se refiere no a la pietas de otros, sino a la suya propia, mientras que solo dos de entre las demás heroínas hablan de su

${ }^{1}$ Dánao, rey de Libia, y Egipto, rey de Egipto, eran dos hermanos que tenían cincuenta hijas y cincuenta hijos respectivamente. Debido a un conflicto relacionado con la soberanía, Dánao, temiendo por su seguridad y la de sus hijas, huyó con ellas a Argos. Los hijos de Egipto los persiguieron, y finalmente convencieron a Dánao para que les diera a sus hijas en matrimonio. Pero después del banquete de bodas, Dánao ordenó a sus hijas que mataran a sus maridos durante la noche (Bonner 1900, p. 27). 
propia cualidad de pia y, además, se refieren a ella una vez aislada, no como clave de su caracterización (Her. I 85; Her. VI 137).

$\mathrm{Al}$ advertir que la pietas de Hipermestra no proviene de la tradición y que es la única heroína de la colección que destaca por esta virtud, surge la cuestión de por qué razón o bajo qué influencia Ovidio se decide por esta caracterización tan concreta y novedosa. Cuando nos encontramos con una relación intertextual entre la Heroida y la Eneida que conecta a Hipermestra con Eneas por su diferente tipo de pietas, que abordaremos a continuación, nos empezamos a plantear la hipótesis de que la construcción por parte de Ovidio de una Hipermestra pia no constituye un desarrollo paralelo, sino que se inspira en el modelo del héroe virgiliano.

Este artículo tiene como objetivo estudiar y comprender la relación que establece Ovidio entre el Eneas virgiliano y su Hipermestra, empezando por analizar un proceso intertextual entre la Eneida y la Heroida XIV que sirve de prueba de la conexión conceptual entre ambos personajes y sus virtudes (Her. XIV 45-50; Aen. VI 678 ss.). En este análisis se tiene en cuenta un factor primordial: cómo afecta a esa relación el hecho de que la pietas femenina y la pietas masculina no son equivalentes ni iguales. A través de este análisis, como veremos, se advierten evidencias de que en la Heroida XIV Ovidio lleva a cabo una deconstrucción del personaje de Eneas a través de su reescritura del personaje de Hipermestra centrada en la pietas. Con la finalidad de comprender este proceso deconstructivo, en este artículo se estudia asimismo la manera en que Ovidio retrata a Eneas en las Heroidas, y se indaga si el héroe virgiliano se configura en la colección como representante de dicha virtud, al igual que en la Eneida. Por último, se aborda la cuestión de por qué, entre todas las heroínas, Ovidio elige a Hipermestra como contrapunto femenino de Eneas.

La metodología utilizada para estudiar la relación propuesta entre ambos pasajes de la Eneida y la Heroida XIV es el análisis literario de corte intertextual. Para analizar el proceso de deconstrucción, se han manejado las nociones de centro y margen con el objetivo de indagar cómo Ovidio desmantela la oposición masculino / femenino (centro / margen) sustituyendo a Eneas por Hipermestra como heroína piadosa. Trabajamos principalmente con textos de la Heroida XIV y la Eneida, y complementariamente con la Oda III 11 de Horacio y la Carta de Dido a Eneas (Her. VII). 
1. Análisis intertextual de Her. XIV 45-50 y Aen. VI 687-688, 697-698, 700-701

El primer punto que vamos a tratar es una prueba intertextual de que Ovidio relaciona la Heroida XIV con la Eneida, y a sus dos protagonistas. Se han señalado en los versos 45-50 de la carta unas alusiones verbales que apuntan a un intertexto del libro VI de la Eneida (Palmer 1989, p. 414; Reeson 2001, p. 258; Battistella 2011, p. 3 ss.). En dicho pasaje de la Heroida, Hipermestra, mientras recuerda la noche de bodas en la que debía matar a Linceo por orden de su padre, se centra en describir su conflicto interno y la manera en que llegó a decidirse por no cometer el asesinato:

Non ego falsa loquor; ter acutum sustulit ensem, ter male sublato decidit ense manus.

[Admoui iugulo (sine me tibi uera fateri), admoui iugulo tela paterna tuo,]

sed timor et pietas crudelibus obstitit ausis, castaque mandatum dextra refugit opus². (Her. XIV 45-50)

El hipotexto de la Eneida se encuentra en el contexto del reencuentro de Anquises y Eneas en el Hades (Aen. VI 678 ss.). Comienza diciendo Anquises: Venisti tandem, tuaque exspectata parenti / uicit iter durum pietas? ${ }^{3}$ (Aen. VI 687-688); a lo que Eneas responde: Da iungere dextram, / da, genitor, teque amplexu ne subtrahe nostro (Aen. VI 697-698), y luego dice el narrador: Ter conatus ibi collo dare brachia circum; / ter frustra comprensa manus effugit imago (Aen. VI 700-701).

Palmer (1989, p. 414) y Reeson (2001, p. 258) únicamente señalan que en la Heroida la repetición de ter evoca descripciones de intentos fallidos en poesía épica anterior (Aen. II 792-793, VI 700-701; Hom., Il. XVIII 155-158, Od. XI 206-208)4. Es Battistella (2011) quien extiende el intertexto virgiliano a los

\footnotetext{
2 Texto latino de Moya del Baño 1986.

3 Texto latino de Greenough 1900.

${ }^{4}$ Que Ovidio utilice el intertexto virgiliano para enfatizar el carácter piadoso de esta es una muestra de que el pasaje de la Eneida, que a su vez evoca a la Ilíada y la Odisea, se convierte en texto autorizado como ejemplo paradigmático de la piedad del héroe. De este modo, en la Heroida las nuevas connotaciones que Virgilio le confiere al pasaje intertextual predominan sobre la evocación del modelo griego.
} 
versos 687-688 y 697-698, pues encuentra alusiones verbales también en pietas y en dextra. Esta estudiosa apunta que el gesto de las «tres veces» arrastra un contexto marcado de piedad ${ }^{5}$ filial, que Ovidio integra en su texto a partir de tres elementos alusivos al pasaje de la Eneida: ter, dextra, pietas (Battistella 2011 , p. 4). Considera que aquí la intertextualidad marca una oposición ideológica, sobre todo en lo referido al género literario: por un lado, la épica, con la pietas tradicional, y por otro, la elegía, con la pietas dirigida al marido. Creemos que Battistella establece un buen punto de partida y que en efecto la relación intertextual que se produce es de oposición, aunque por nuestra parte consideramos que no es tanto que Ovidio elija la pietas de la elegía, sino que se sirve de ella para desmontar la de la épica. Además, pondremos énfasis en un elemento que Battistella pasa un tanto por alto: el hecho de que esa pietas tradicional de la épica es de carácter masculino frente a la pietas femenina de la Heroida. A continuación, vamos a dedicarnos a analizar este proceso intertextual en profundidad fijándonos en cómo las alusiones verbales crean una relación contrapuesta entre Eneas e Hipermestra.

En el citado pasaje de la Heroida, tras un comentario parentético en el que la escritora intenta ganarse el favor del lector mostrando sinceridad (Non ego falsa loquor, Her. XIV 45), la voz de Hipermestra, con un tono narrativo, describe cómo estuvo a punto de cometer el crimen varias veces (ter acutum sustulit ensem, Her. XIV 45), tantas como se arrepintió por sus propias reservas morales ( $\underline{\text { Ter }}$ male sublato decidit ense manus, Her. XIV 46). Analicemos con más detalle el pasaje intertextual comenzando por la relación ter-ter:

Non ego falsa loquor, ter acutum sustulit ensem,

ter male sublato decidit ense manus (Her. XIV 45-46)

Ter conatus ibi collo dare bracchia circum;

ter frustra comprensa manus effugit imago (Aen. VI 700-701)

La similitud que se ha señalado es evidente: ambos pasajes describen un intento fallido. La estructura de ambos pares de versos es similar, pues con la repetición ter-ter, en el primer verso se dice lo que se intenta (Her. XIV 45; Aen. VI 700) y en el segundo cómo no se consigue (Her. XIV 46; Aen.

${ }^{5}$ En este artículo se opta por traducir pietas y pia como 'piedad' y 'piadosa' respectivamente. 
VI 701). Este segundo par de versos es especialmente paralelístico: ambos comienzan con una estructura ter + adverbio + participio, y además comparten otro eco verbal en manus, que analizaremos enseguida.

Otra similitud se encuentra en el modo de enunciación. En una carta lo esperado es que una primera persona se dirija a una segunda, algo que no ocurre en este dístico de la Heroida, quizás como forma de mimetizarse con el intertexto narrativo: de igual manera que en el intertexto virgiliano la escena del abrazo frustrado está en boca del narrador externo, Ovidio sitúa la descripción del intento de Hipermestra de cometer el asesinato en la voz narrativa de la escritora, que relata la escena en tercera persona como si la viera desde fuera, convirtiendo su mano en sujeto de la acción (decidit ... manus, Her. XIV 46).

No obstante, aunque ambos pares de versos describan intentos fallidos con elementos similares, hay una divergencia significativa en el contenido. Los actos que se repiten tres veces son diferentes e incluso opuestos: en la Enei$d a$ son tres los intentos del héroe de abrazar el cuello del padre; en la Heroi$d a$ son tres los intentos de la heroína de cortarle el cuello a su esposo, o, dicho de otra manera, tres intentos de cumplir la orden de su padre. La diferencia en el contenido se refleja textualmente. Por un lado, los dos versos de la Eneida (Aen. VI 700-701) describen un mismo acto: Eneas intenta abrazar a Anquises y al mismo tiempo fracasa; pero Hipermestra primero levanta la mano (Her. XIV 45) y luego la baja (Her. XIV 46), lo cual manifiesta un conflicto interno y, quizás más importante, que el intento de Hipermestra, a diferencia del de Eneas, no es tanto un intento frustrado como una decisión consciente de no hacer lo que intentaba.

En el segundo par de versos (Her. XIV 46; Aen. VI 701) se aprecia bien esta divergencia, especialmente si comparamos los adverbios. Ovidio sitúa male (male sublato ... ense, Her. XIV 46) en el mismo lugar de verso que frustra (frustra comprensa ... imago, Aen. VI 701), subrayando así el contraste entre que Eneas hace algo en vano y el hecho de que Hipermestra decide no hacer algo porque lo considera incorrecto. De esta forma, se genera una oposición entre comprensa ... imago (Aen. VI 701) y male sublato ... ense (Her. XIV 46), pues la primera es signo de pietas, mientras que el segundo es una muestra de impiedad. En este punto abordamos también el hecho de que, aunque ambos héroes actúan por pietas, esta virtud se aplica de diferente manera en cada caso: Eneas falla al intentar algo que su pietas, de carácter filial, le lleva a hacer, mientras que Hipermestra decide fracasar en su pietas 
filial para triunfar en su pietas conyugal, como veremos con más detalle más adelante.

Manus (Her. XIV 46; Aen. VI 701) también es importante como elemento de comparación que subraya la diferencia en la pietas de ambos personajes. Las manos de Eneas son piadosas al intentar abrazar al padre, pero la mano de Hipermestra se encuentra en esa complicada ambivalencia moral: en el verso 45, cuando levanta la espada, su mano es piadosa para con su padre pero impía para con su marido; sin embargo, en el verso 46 es piadosa para con su marido e impía para con su padre. En lo que respecta a las manos como elemento de comparación antitética, conviene hacer referencia en este punto a la conexión entre el verso 50 de la Heroida y 701 de la Eneida, pues en ambos casos aparece la idea de «mano» junto con el concepto de «rehuir», reforzando una comparación contrapuesta (Castaque mandatum dextra refugit opus, Her. XIV 50; ter frustra comprensa manus effugit imago, Aen. VI 701). En este intertexto, el elemento del fantasma del padre que escapa a las manos piadosas del hijo es trasladado por Ovidio irónicamente a la voz de Hipermestra, de manera que es ella quien rehúye la orden de su padre con un acto de su mano impía.

Analicemos el siguiente par de versos. Como se acaba de ver, Hipermestra ha introducido su conflicto interno contando que intentó varias veces cometer el asesinato, pero que se decidió siempre por no hacerlo (Her. XIV 45-46). A continuación, la escritora realiza una operación de expansión de la descripción contenida en 45-46, pues cuenta, ahora en primera persona, cómo intentó acercar el cuchillo al cuello (Her. XIV 47-48).

El dístico 47-48 de la carta (Admoui iugulo (sine me tibi uera fateri), / Admoui iugulo tela paterna tuo, Her. XIV 47-48) describe el mismo intento de asesinato que el verso 45 (Non ego falsa loquor, ter acutum sustulit ensem, Her. XIV 45). Incluso se evidencia una similitud en la forma, pues se vuelve a utilizar un comentario parentético de contenido similar (Non ego falsa loquor, Her. XIV 45; sine me tibi uera fateri, Her. XIV 47). Sin embargo, existe una divergencia significativa en el modo de enunciación. Como se ha visto, en 45-46 la escritora de la carta se convertía en una narradora en tercera persona que observaba la escena desde fuera - pese a ser ella misma la protagonista-. Ahora, en 47-48, la escritora describe en primera persona cómo acercó el cuchillo al cuello de su esposo (admoui, Her. XIV 47, 48). Además, la voz de Hipermestra se refiere al objeto del relato, Linceo, en segunda persona (iugulo ... tuo, Her. XIV 48), y se dirige a él en el parénte- 
sis (sine me tibi uera fateri, Her. XIV 47), a diferencia del comentario del verso 45, que carece de interlocutor explícito.

Esta voz en primera persona con un lector interno se acerca más a la voz subjetiva de la lírica o la elegía, lo cual puede verse justificado si tenemos en cuenta un intertexto lírico de este dístico: los versos 30-32 de la Oda III 11 de Horacio, un poema que resulta un referente importante en la composición de la Heroida porque el autor da voz a Hipermestra y la representa en la noche de bodas avisando a Linceo para que huya. En lo que respecta específicamente al dístico que estamos estudiando de la Heroida, Reeson (2001, p. 260) apunta, en favor de la variante III del verso $47^{6}$, que en la oda de Horacio hay un recurso retórico del que puede estar haciéndose eco Ovidio:

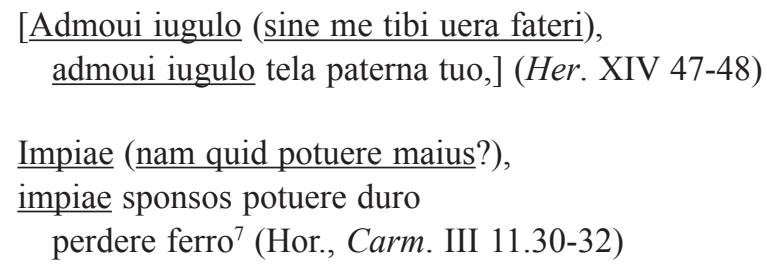

[Admoui iugulo (sine me tibi uera fateri), admoui iugulo tela paterna tuo,] (Her. XIV 47-48)

Impiae (nam quid potuere maius?), impiae sponsos potuere duro perdere ferro ${ }^{7}$ (Hor., Carm. III 11.30-32)

En efecto, en ambos textos se encuentra una frase que, tras ser interrumpida por un comentario parentético, repite su comienzo en el siguiente verso. En el intertexto horaciano se sitúa el foco en la impiedad de las hermanas por cometer el asesinato, de modo que el acto impío que intenta cometer Hipermestra (Admoui iugulo, Her. XIV 47-48) queda identificado intertextualmente con el acto impío que en efecto cometen sus hermanas (impiae, Hor., Carm. III 11.30-31). Sin embargo, en el caso de nuestra heroína, es un acto que se queda en intento, lo que hace prevalecer su piedad conyugal. Así, el texto de la Heroida, con la referencia al hipotexto de Horacio, recuerda la impiedad de las hermanas para subrayar la piedad de la heroína. O, dicho de otra manera, Ovidio reescribe la voz poética de Horacio, que critica el crimen

${ }^{6}$ El verso 47 es de complicada transmisión textual. La variante III, Admoui ingulo (sine me tibi uera fateri), parece ser la preferida de los editores (Ehwald 1907; Palmer, 1898; Moya del Baño 1986; Ramírez de Verger 2005). Creemos que el proceso intertextual que hay en los versos 45-50 se enriquece con la lectura de III, por lo que efectuamos el análisis considerando que III puede ser o bien la versión original del verso, conservado en parte por la tradición, o bien un buen intento de restauración, como apunta Reeson (2001, p. 260).

${ }^{7}$ Edición del texto latino de Shorey y Laing 1919. 
de las hermanas, en una voz que defiende el carácter piadoso de la única que no cometió el asesinato.

A lo anterior hay que añadir que Horacio también aprecia una virtud en Hipermestra, aunque no es la pietas, sino la clementia: Me pater saeuis oneret catenis, / quod uiro clemens misero peperci (Hor., Carm. III 11.45-46). No obstante, en Horacio la motivación de la decisión de Hipermestra no es tanto la virtud de la clementia, sino el amor: el amor la hace perdonar la vida a su marido y como consecuencia de ello es clemens. La Hipermestra ovidiana tiene una motivación diferente de la de su predecesora literaria, como expresa en el siguiente dístico: Sed timor et pietas crudelibus obstitit ausis, / castaque mandatum dextra refugit opus (Her. XIV 49-50). Este dístico, como hemos señalado, está vinculado intertextualmente a unos versos de la conversación entre padre e hijo en la Eneida, principalmente mediante la evocación verbal de pietas y dextra. Anquises dice: Venisti tandem, tuaque exspectata parenti / uicit iter durum pietas? (Aen. VI 687-688); y luego Eneas: Da iungere dextram, / da, genitor, teque amplexu ne subtrahe nostro (Aen. VI 697-698). De esta manera, Ovidio, después de hacer una referencia al intertexto de la oda (Her. XIV 47-48; Hor., Carm. III 11.45-46), presenta la motivación de su heroína en unos versos que retoman el mismo intertexto de la Eneida que tenían los versos 45-46. Ovidio, así, se aparta de las razones de la Hipermestra horaciana y al mismo tiempo señala la pietas de Eneas como referente.

Analicemos la relación entre Her. XIV 49-50 y Aen. VI 687-688, 697-698. En la Eneida tenemos un pasaje dialogado en el que el padre se alegra de la visita de su hijo y el hijo desea abrazarlo, mientras que en la Heroida solo encontramos la voz de Hipermestra dando las razones por las que desobedeció a su padre. Esta diferencia en el contexto tiene sus consecuencias intertextuales. En la Eneida, la pietas de Eneas se encuentra en boca de su padre y es una pietas claramente filial de la que Anquises se siente orgulloso (tuaque exspectata parenti ... pietas, Aen. VI 687-688); por el contrario, en la Heroida, es Hipermestra quien defiende su propia pietas. Esto es significativo no tanto desde el punto de vista de la voz de los personajes como por lo que implica en el nivel del autor y el lector externos: es la primera vez que se habla de la pietas de Hipermestra y Ovidio la presenta en el texto sin adjetivar, dejando aparentemente abierta las posibilidades semánticas de este ambivalente concepto (Sed timor et pietas crudelibus obstitit ausis, Her. XIV 49). Esto contrasta con los tres determinantes que tiene la pietas en el texto de la Eneida (tuaque exspectata parenti ... pietas, Aen. VI 687-688). 
En exspectata pietas se produce un caso de reflexividad, pues en boca de Anquises sirve simplemente para expresar que él esperaba o deseaba la pietas de su hijo, pero desde el punto de vista del autor y los lectores externos, Virgilio se hace eco de que la pietas es el rasgo más conocido del héroe. Al contrario, en la Heroida, en el nivel de los personajes, la pietas de Hipermestra no solo no es parenti sino que es una pietas que daña a su padre, y por ello nunca sería reconocida por él. Asimismo, los lectores externos tampoco reconocen la pietas de la heroína puesto que es un rasgo que Ovidio subraya por primera vez.

No obstante, lo más interesante para ver los diferentes tipos de pietas es que Ovidio reescribe un símbolo de parenti pietas de este texto de la Eneida, la dextra de Anquises que Eneas desea agarrar (Da iungere dextram. / da, genitor, teque amplexu ne subtrahe nostro, Aen. VI 697-698), y lo convierte en símbolo de otro tipo de pietas (castaque mandatum dextra refugit opus, Her. XIV 49-50). En la Heroida, dextra es la mano de la propia Hipermestra, y al no cometer el asesinato, se transforma en un símbolo de su piedad conyugal, como muestra la adjetivación casta dextra (50), que contrasta con la adjetivación de parenti pietas y señala los valores clave para cada personaje. De esta manera, Hipermestra no necesita calificar la pietas, pues para ella solo hay un tipo, la conyugal.

Fijémonos para finalizar en que la palabra pietas en la Heroida no forma un sintagma independiente, sino que está en conjunción con timor (timor et pietas, Her. XIV 49). Creemos que con esta unión Ovidio relaciona el rasgo nuevo que él busca darle a su heroína con la motivación tradicional de su pasado literario que se encuentra en Propercio (IV 7.63-68) y se remonta hasta Esquilo (Pr. 868): el temor femenino a tomar una espada y llevar a cabo un asesinato. Por ello, interpretamos que el sintagma timor et pietas también es un punto de reflexividad, como lo es exspectata pietas: por un lado, en la voz de la heroína, el timor es un miedo a lo que pueda pasarle si no es piadosa, por eso se encuentra unido a pietas; pero, por otro lado, en el nivel de la voz de Ovidio, timor et pietas apunta a ambas motivaciones: el timor de su pasado literario que el lector crítico conoce y la nueva pietas que Ovidio concibe para ella. Asimismo, timor et pietas puede entenderse como una hendíadis: la «temerosa piedad» o «el temor piadoso», lo cual refuerza la idea de la clase de piedad femenina que defendemos.

Habiendo analizado el pasaje intertextual completo, consideramos que Ovidio refleja en la jerarquía de sus intertextos su decisión consciente de crear una Hipermestra caracterizada por la pietas. Hemos estudiado los versos 45-50 de la Heroida XIV en relación con su intertexto principal (Aen. VI 
678 ss.) y secundario (Hor., Carm. III 11.30-32), que podemos recapitular de la siguiente manera. El pasaje comienza con un tono narrativo (Her. XIV 45-46) conectando intertextualmente la escena de la carta en que Hipermestra decide actuar por su pietas (conyugal) con una escena de la Eneida en la que Eneas demuestra su pietas (filial). Seguidamente (Her. XIV 47-48) el tono de la escritora se torna subjetivo y el texto alude a unos versos de uno de los pasados literarios de la heroína (Hor., Carm. III 11.30-32), en los que la voz poética del autor critica la impiedad de las Danaides. A continuación (Her. XIV 49-50), la escritora retoma el tono narrativo y aparecen los otros dos elementos alusivos al pasaje de la Eneida, dextra y, especialmente, pietas, la palabra clave que caracteriza al pasaje y por extensión al comportamiento de la Hipermestra ovidiana. En este sentido se puede concluir que la palabra foco del intertexto horaciano, impiae, se aplica en oposición a Hipermestra y se refuerza como carácter moral heroico de esta al relacionarlo con Eneas y el intertexto virgiliano, que se encuentra en posición marcada al principio (Her. XIV 45-46) y al final (Her. XIV 49-59). Se aprecia por tanto una compleja mezcla de elementos intertextuales que configuran a la Hipermestra de la carta como la heroína que Ovidio quiere que sea gracias a alusiones en oposición y a la colocación específica de los intertextos destacados.

Mediante este análisis intertextual se ha procurado demostrar que la conexión que crea Ovidio entre los versos de la Heroida XIV y el citado pasaje de la Eneida sirve para establecer una relación de oposición entre Hipermestra y Eneas. Consideramos que esta relación, esta forma de reescribir a Hipermestra a la luz de Eneas, pero al mismo tiempo muy diferente, no es consecuencia de un simple juego paródico por parte de Ovidio ni una sencilla variación del tema de la pietas según el género sociológico del sujeto. Visto todo lo anterior, para una completa comprensión de este fenómeno, hemos tenido en consideración la línea de estudio que defiende lo que Fernández Corte llama fragmentación (o deconstrucción) ovidiana de la Eneida en las Metamorfosis. Este estudioso defiende que Ovidio, en la llamada «Eneida ovidiana» ${ }^{8}$, realiza una de-

${ }^{8}$ En las interpretaciones deconstructivas que citamos tuvo gran influencia el trabajo de Galinsky (1975, pp. 217-251), quien sostiene que la «Eneida ovidiana» no está fundamentada en mera parodia o trivialización de la Eneida. Este autor sostiene que Ovidio cuenta la historia aliter, no contra, y que propone una alternativa exitosa al tratamiento virgiliano del mito. Según resume Martínez Astorino (2017, p. 198), Solodow coincide con Galinsky en lo anteriormente expuesto, pero afirma que esa visión alternativa constituye una crítica de la Eneida, puesto que la 
construcción del relato magistral de la cultura latina materializado en la Eneida de Virgilio (Fernández Corte 2018, pp. 213-214). Fernández Corte y Cantó Llorca (2008, p. 52 ss.) sostienen que Ovidio fragmenta en las Metamorfosis, entre otras cosas, cuestiones culturales de vasto alcance social que se reunían en la Eneida como obra que había adquirido el carácter de mito fundacional. Uno de estos aspectos es el tipo de heroísmo y de religiosidad de Eneas, y la forma de masculinidad que representa. También señalan, siguiendo a Solodow 1988, pp. 155-156, que el Ovidio deconstructivo se ocupa de presentar una interpretación demoledora del héroe augústeo, pues Eneas no aparece en ningún momento como fundador de la nación romana, no es un personaje central de la narración y no es conspicuo por ninguna virtud: muestra de esto es que solo es llamado pius una vez (Met. XIII 625).

La poca intensidad con la que retrata Ovidio a Eneas como pius en las $\mathrm{Me-}$ tamorfosis contrasta manifiestamente con la insistencia con que el autor había caracterizado a Hipermestra como pia. En este sentido, nos parece sugerente que existan teorías como la que sostiene Fernández Corte que defienden precisamente el mismo tipo de proceso deconstructivo que hemos apreciado paralelamente en la Heroida XIV en una obra posterior del mismo autor. Sin pretender en este artículo entrar a estudiar citada teoría sobre Metamorfosis, nos parece que la deconstrucción que sostenemos de Eneas en la Heroida XIV puede reforzar desde un punto de vista intratextual y diacrónico la teoría de que Ovidio en las Metamorfosis efectúe una fragmentación de la epopeya y de su héroe.

Dicho todo lo anterior, para afirmar que en efecto en las Heroidas Ovidio realiza una fragmentación del héroe, no basta con confirmar la relación de oposición entre Hipermestra y Eneas, como se ha hecho en este epígrafe. Se debe demostrar que en esta obra el autor pretende situar a Eneas en el margen. Como en la Heroida XIV el héroe virgiliano no tiene presencia efectiva, es conveniente fijarse en cómo es retratado en la Carta de Dido (Her. VII), con el objetivo de determinar si Ovidio lo presenta como el modelo virgiliano prototípico de pietas, o, por el contrario, si se convierte en un personaje secundario alejado de los valores centrales que manifiesta la obra.

Eneida y Eneas no son, para Ovidio, el tema y el personaje central. En este punto nos remitimos asimismo a Martínez Astorino 2003-2004, pp. 97-99, donde encontramos un claro resumen del estado de la cuestión de la «Eneida ovidiana» desde principios del siglo XX. Por otra parte, conviene apuntar que recientemente la crítica española ha realizado interesantes aportaciones a este tema (Álvarez Morán e Iglesias Montiel 2004, 2009; Estefanía 2018). 


\section{Eneas en la voz de Dido (Her. VII y Aen. IV): el impius Aeneas}

En su carta, Dido no llama a Eneas pius ninguna vez, siempre lo caracteriza con léxico relacionado con el engaño y la traición (fallas, Her. VII 20; infidum, Her. VII 30; male gratus, Her. VII 27; inique, Her. VII 45; perfide, Her. VII 79, 118; scelerate, Her. VII 133). No obstante, Dido utiliza el adjetivo pius en dos ocasiones.

El primer ejemplo es pia tura. Se encuentra en un contexto en el que Dido se presenta como la esposa que más va a querer a Eneas (Vnde tibi, quae te sic amet, uxor erit?, Her. VII 24), para lo que utiliza símiles de elementos nupciales: primero se compara a sí misma con la antorcha por su ardiente amor (Vror, ut inducto ceratae sulphure taedae, Her. VII 25) y a continuación compara a Eneas con el incienso (ut pia fumosis addita tura rogis / Aeneas oculis uigilantis semper inhaeret, Her. VII 25a-25b). Ovidio utiliza este mismo sintagma pia tura en Amores (Et quisquam pia tura focis inponere curat?, Am. III $3.33^{9}$ ), que remite intertextualmente a Tibulo ${ }^{10}$ (urantur pia tura focis, Tib. II 2.3 ${ }^{11}$ ). En estos dos textos el incienso es piadoso porque se utiliza para honrar a los dioses en diferentes contextos. Pensamos que en la voz de Dido pia tura se refiere en concreto a un incienso destinado a honrar a los dioses del matrimonio por el contexto erótico y porque se pretende presentar a sí misma como la mejor esposa posible para Eneas, como hemos visto ${ }^{12}$. Si analizamos el símil, observaremos que Dido compara el incienso con Eneas para decir que no puede dejar

${ }^{9}$ Edición del texto latino de Ehwald 1907.

${ }^{10}$ En su elegía Ovidio se queja de que su amada le ha jurado fidelidad en falso. Así, esta relación intertextual de pia tura entre la Heroida VII y Amores III 3 identifica a Ovidio con Dido, que también está sufriendo la traición de Eneas. Por otra parte, el poema de Tibulo trata sobre la celebración de un cumpleaños, y por tanto no tiene un tema amoroso; sin embargo, en la Heroida Ovidio toma urantur y lo transfiere a su texto confiriéndole significado erótico (uror, Her. VII 25).

${ }^{11}$ Edición del texto latino de Postgate 1915.

12 Pese a la claridad del contexto amoroso, hay un giro en el horizonte de expectativas del lector crítico, pues el incienso de la Heroida no es arrojado a los focis, como en los intertextos, sino a los rogis: de esta manera, a lo que era un símil amoroso se le añaden connotaciones funerarias que remiten a la pira en la que morirá la Dido virgiliana. Aquí hay una intersección de voces de Ovidio como autor real y Dido como escritora de la carta: en un contexto amoroso se inserta en la voz de la heroína una referencia a su trágico futuro que los lectores externos conocemos y que está prefijado en la epopeya de Virgilio. Incluso podemos decir que en la Heroida (VII 24-25b) hay una intersección entre las voces de la Dido ovidiana y 
de mirarlo: el troyano se pega a los ojos de Dido tanto como el incienso a la pira. Resulta interesante que se compare pia tura con el pius Eneas porque es una equivalencia irónica: el incienso es piadoso porque sirve para honrar a los dioses nupciales, mientras que Eneas, al abandonar a Dido, está actuando contra esos mismos dioses, y por lo tanto no es pius.

Pero pia tura sobre todo nos interesa intratextualmente en una conexión que se establece entre la Carta de Dido y la Carta de Hipermestra. En la carta de Hipermestra podemos encontrar impia tura (Her. XIV 26). Cuando esta heroína describe la noche de bodas, se refiere al incienso como impío pues se está utilizando para honrar una boda que en realidad es un engaño para asesinar a los maridos, y, por tanto, todo lo relacionado con ella deshonra a los dioses y va en contra de la piedad conyugal. La Carta de Dido y la Carta de Hipermestra son las únicas de la colección en las que tura está adjetivado con palabras de la familia léxica de pietas, y precisamente se encuentran en oposición pia tura / impia tura. Creemos que esta relación vincula ambas cartas por el valor por el que el autor quiere que las comparemos: la pietas. En la historia canónica de Dido, Eneas es el representante de la pietas, mientras que en la historia de Hipermestra, sus hermanas son impiae. Sin embargo, en ambas cartas Ovidio pone de relieve las perspectivas marginales: la piedad de Hipermestra y la impiedad de Eneas - de la que hablaremos con más detalle enseguida-, características que habían pasado desapercibidas al pensamiento hegemónico.

En el otro caso del uso del adjetivo pius en la Carta de Dido también se puede apreciar una referencia a la impiedad de Eneas. Este segundo ejemplo es seniorque pater, pia sarcina nati (Her. VII 107). El adjetivo pius está determinando al padre, Anquises: es una metonimia con la cual se refiere realmente a la piedad que Eneas muestra al cargar con su padre. Con este recurso Dido, u Ovidio, hábilmente evitan llamar directamente a Eneas pius. Además, estas palabras están en un contexto en el que Dido justifica haber violado el pudor alegando que ella tenía todas las razones para pensar que Eneas se casaría con ella (Her. VII 105-110). Por lo cual no podemos evitar advertir en pia sarcina un tono irónico desde la perspectiva de una Dido cuyas expectativas de la fama de Eneas se han desvanecido junto con su abandono y su traición: vemos así una puesta en duda de esa exspectata pietas.

la Dido virgiliana, pues el tono erótico es de la ovidiana y el funesto es de la virgiliana, en cuya boca se encuentra la palabra rogus (Aen. IV 640, 646). 
Y siguiendo por ese camino, conviene añadir que Dido se refiere directamente a la impiedad de Eneas, de nuevo mediante una metonimia: Non bene caelestis impia dextra colit (Her. VII 130). La escritora pone en duda que Eneas sea el piadoso héroe que debe honrar a los dioses patrios que sacó de Troya. Antes dijo que ella se había equivocado al confiar en un hombre famoso por su madre divina y la piadosa carga de su padre (Her. VII 107-108); ahora le niega también su deber para con los dioses patrios. Puesto que Dido califica de impia la mano de Eneas precisamente cuando se queja del abandono y de la falta de fidelidad del héroe, consideramos que se refiere concretamente a la impiedad conyugal de Eneas.

En definitiva, se manifiesta que la Dido ovidiana relaciona a Eneas con la impiedad conyugal. Para ver cómo esto forma parte de la deconstrucción ovidiana de Eneas conviene estudiar si la impiedad del héroe en boca de Dido es un elemento tomado de la Eneida de Virgilio. En la Eneida, encontramos el adjetivo impius en la voz de Dido en dos ocasiones (Aen. IV 496, 596), ambas después de que Eneas le confirme que se va a marchar.

El primer ejemplo se encuentra en el discurso con el que Dido convence a su hermana de que prepare la pira en la que quemar los recuerdos de Eneas como un supuesto ritual que le haría olvidar su amor:

Tu secreta pyram tecto interiore sub auras erige, et arma uiri, thalamo quae fixa reliquit impius, exuuiasque omnis, lectumque iugalem, quo perii, superimponas ... (Aen. IV 494-497)

En este texto parece suficientemente claro que impius se refiere a Eneas. Pero impius, como sabemos, puede tener muchos matices. Si analizamos el contexto veremos a qué tipo de impiedad se refiere. Dido habla de las armas y las prendas que se ha dejado Eneas en su cuarto, y en último lugar hace mención al lecho nupcial. Y mientras recuerda cómo el héroe se ha acostado con ella y ha traicionado el vínculo que eso supone ${ }^{13}$, lo llama impius. Dido se refiere a un tipo concreto de impiedad: la conyugal.

${ }^{13}$ La existencia de un vínculo matrimonial entre Eneas y Dido resulta controvertida. El propio Eneas considera que, como él no ha prometido nada, no hay ningún matrimonio que romper (Aen. IV 339). La postura del narrador es ambigua, pues en determinado momento parece confirmar la versión de Eneas (coniugium uocat; hoc praetexit nomine culpam, Aen. 
El segundo ejemplo se encuentra en el discurso que Dido pronuncia cuando observa las naves troyanas alejarse.

Infelix Dido, nunc te facta impia tangunt.

Tum decuit, cum sceptra dabas.-En dextra fidesque, quem secum patrios aiunt portare Penates, quem subiisse umeris confectum aetate parentem! (Aen. IV 596-599)

Se ha escrito mucho sobre el significado de facta impia. Consideramos que la interpretación de Casali 1999, que atribuye las acciones impías a Eneas, es la más acertada. La mayoría de la crítica opina que facta impia son los actos impíos contra el pudor que ha cometido la propia Dido, pero según Casali (1999, pp. 203, 206), incluso los que se las han asignado a Eneas han fallado en explicar qué acciones son y por qué Dido dice que debería haber sabido que confiar en Eneas era un error (Aen. IV 596-597). Casali (2003, p. 66) interpreta que Dido, cuando Eneas la abandona, se da cuenta de que la narración de este sobre cómo escapó de Troya gracias a su comportamiento piadoso, contenida en el libro II de la Eneida, es una mentira, y que si escapó fue por sus facta impia, es decir, gracias al engaño y la traición. Según apunta Casali (1999, p. 206, n. 6), en la antigüedad había dos versiones de la huida de Eneas de Troya, una es la que se cuenta en la Eneida y otra según la cual el héroe entregaba Troya a los griegos y por ello le permitieron escapar con vida a él y su familia. Este autor añade además que Eneas en el libro II proporciona esta versión de su huida porque es la que Virgilio debía dar, pero que mediante estas palabras de Dido (Aen. IV 596-599), el autor muestra que las versiones descartadas del mismo hecho pueden mantener su validez para otros (Casali 1999, p. 210).

Esta interpretación explica bien una cuestión compleja desde el nivel del lector y autor externos. Pero desde el punto de vista interno del personaje de Dido, existe una explicación sencilla que es coherente con la otra ocasión en que Dido utiliza el adjetivo impius refiriéndose a su amado traidor. De nuevo, analicemos el contexto. La heroína se queja con dolor de la traición de Eneas, y la frustración de sus expectativas le obliga a referirse, exclamando con amarga

IV 172), pero, unos versos antes, había llamado a su unión conubiis (Aen. IV 168). Asimismo, no solo Dido considera que la unión física supone una unión matrimonial efectiva, sino que así lo expresa también la propia Juno, quien los une en matrimonio (conubio iungam stabili propriamque dicabo, / hic hymenaeus erit, Aen. IV 126-127). 
ironía, a aquellas cosas que le hicieron confiar en él, cuestionando la credibilidad de los signos de fidelidad que el héroe le ofreció (dextra fidesque, Aen. IV 597) y la propia fama de piadoso por cargar con su padre y los penates (Aen. IV 598599). Sostenemos que Dido dice que ahora le afectan los actos impíos de Eneas (Aen. IV 596) porque, al ver que la abandona, recuerda que en la historia de la huida que él mismo le contó comete un importante acto impío: Eneas abandonó a su esposa Creúsa. En ese momento no se dio cuenta de que lo mismo le pasaría a ella, de que Eneas volvería a traicionar el vínculo matrimonial y volvería a poner por delante su concepto masculino de pietas. Dido parece no tener ninguna duda: aunque Eneas quiera presentarse como pius, en realidad es impius Aeneas. Para ella, al igual que para Hipermestra, solo existe un tipo de pietas, y quien no se comporte según esa virtud es impío, ya sea hombre o mujer.

En ningún otro lugar de la Eneida se le llama a Eneas impius, solo estas dos veces en boca de Dido. Virgilio sitúa esta interpretación del impius Aeneas en la voz de un personaje femenino, colocando claramente esta lectura en el margen -prueba de ello es que la mayoría de los críticos hayan interpretado facta impia como los actos impúdicos de Dido-. Pero, aunque sitúe la impiedad de Eneas en el margen, lo importante es que la sitúa. Y en este sentido se puede ver en la Eneida una relación de oposición entre la piedad y la impiedad del héroe en dos momentos clave que están conectados intratextualmente: los versos 700-701 del libro VI de la Eneida -el intento frustrado de abrazar a Anquises que hemos analizado como pasaje que se convierte en modelo de piedad filial para la Heroida XIV - reiteran con exactas palabras los versos 792-793 de la escena del libro II en la que el fantasma de Creúsa le dice a Eneas que debe proseguir su camino sin ella:

Ter conatus ibi collo dare bracchia circum: ter frustra comprensa manus effugit imago (Aen. II 792-793)

Ter conatus ibi collo dare bracchia circum; ter frustra comprensa manus effugit imago (Aen. VI 700-701)

Aunque Eneas regresa a buscar a Creúsa (Aen. II 750 ss.) y tiene su consentimiento para marcharse (Aen. II 775 ss.), el hecho es que prioriza absolutamente la salvación de su padre, no la de su esposa, lo cual resulta una muestra de impiedad conyugal que luego repite con Dido. Este pasaje intratextual (Aen. II 792-793, VI 700-701) subraya especialmente la impiedad conyugal del héroe porque son palabras exactamente iguales aplicadas a un 
contexto muy distinto, lo cual sirve para subrayar la divergencia: en este caso, impiedad conyugal frente a piedad filial. Dos caras de Eneas, una hegemónica, otra marginal.

En conclusión, Ovidio toma de la Eneida esta lectura minoritaria sobre Eneas para su carta de Dido. Pero es cierto que la Dido ovidiana no insiste más que la virgiliana en la impiedad de Eneas, y, por tanto, el impius Aeneas no es una innovación de Ovidio. Lo verdaderamente relevante es que en la colección de Heroidas el único Eneas que existe es el impius, y por tanto Ovidio la convierte en la lectura central. En eso consiste precisamente la deconstrucción: con un comportamiento perfectamente análogo por parte de Dido, el Eneas impius es central en las Heroidas, pero marginal en la Eneida, porque las características del género literario de cada obra y, sobre todo, la perspectiva de las mismas, permiten invertir este elemento, aun siendo objetivamente igual. A esto hay que añadir que, más allá de la deconstrucción particular que puede apreciarse en las Heroidas, el retrato crítico directo o indirecto de Eneas obedece también, formalmente, a una pretensión de género literario y a la elección de un tipo específico de elegía, pues dicha deconstrucción es un elemento que integra una dinámica general de la colección, entendida como una suerte de revisión de los mitos, en la que se observa, de manera generalizada, el punto de vista de las mujeres.

\section{3. ¿Por qué Hipermestra?}

Recapitulando lo que se ha señalado hasta ahora, Ovidio, tras presentar la cara marginal del Eneas impío en la Heroida VII, crea a una Hipermestra representante de la piedad conyugal en la Heroida XIV, y se sirve de ello para seguir situando en el margen a Eneas y sus valores poniendo de relieve el tipo de pietas que él rompe. Pero en la colección hay otras heroínas que podrían ser representantes de la pietas conyugal, y de manera mucho más reconocible por el lector, como por ejemplo Penélope (Her. I). Ante esta circunstancia, la pregunta que surge es: ¿por qué Hipermestra?

Hay una razón definitiva por la que sostenemos que Ovidio eligió precisamente a Hipermestra para deconstruir a Eneas, y tiene que ver con el final de la Eneida. Como es sabido, en el final de la epopeya virgiliana, el héroe, cuando está a punto de ceder a las súplicas del Turno derrotado, observa que este lleva puesto el tahalí de Palante, que le recuerda los deberes del pacto de hospitalidad establecido con Evandro, y finalmente acaba con su vida 
(Aen. XII 930-952). Se ha escrito mucho sobre este final y sus interpretaciones ${ }^{14}$. Como señala Edgeworth $(2005$, p. 7$)$, los dos principales puntos de vista pueden describirse como optimistas y pesimistas. A los optimistas pertenecen Karl Galinsky, Hans-Peter Stahl, Francis Cairns, Viktor Pöschl y Brooks Otis. Según ellos, Eneas actúa correctamente matando a Turno y rechazando su súplica de misericordia. A los pesimistas pertenecen Michael Putnam, Richard Thomas, R. O. A. M. Lyne, Steven Farron, y W. R. Johnson. Para ellos Eneas falla en su misión, pues abandona sus obligaciones con la pietas y la clementia, rindiéndose ante el furor.

En lo que respecta al tema particular de este artículo, nos interesa fijarnos en el significado del tahalí de Palante en este desenlace, pues está decorado con la imagen de las Danaides cometiendo el asesinato de sus esposos, como se describe en el libro X:

Et laeuo pressit pede talia fatus exanimem, rapiens immania pondera baltei impressumque nefas, una sub nocte iugali caesa manus iuuenum foede thalamique cruenti, quae Clonus Eurytides multo caelauerat auro; quo nunc Turnus ouat spolio gaudetque potitus. (Aen. X 495-500)

La escena del tahalí se centra en las Danaides y en el asesinato que cometen; Hipermestra y su perdón no aparecen representados. Edgeworth (2005, pp. 4,10$)$ sostiene una interesante interpretación del significado de las Danaides en la Eneida. Este autor considera que Virgilio no sitúa a las hermanas entre su lista de condenados en el infierno ${ }^{15}$ (Aen. VI 580-627) para subrayar la ambivalencia, indicando al lector que la acción de las Danaides es al mismo tiempo piadosa, por obedecer al padre, y nefas, por el asesinato. Edgeworth cree que Virgilio aplica el simbolismo de las Danaides a la decisión final de Eneas, de tal manera que Eneas es pius y nefas al mismo tiempo. En esa misma situación ambivalente se encuentran Hipermestra y las hijas de

${ }_{14}$ Para un estado de la cuestión nos remitimos a Ceccarelli 2012, citado por Estefanía (2017, p. 33).

${ }^{15}$ La mayoría de las obras latinas que tratan la historia de las hijas de Dánao antes que las Heroidas se centran en el crimen de las hermanas y, a excepción de la Eneida, las sitúan por ello en el infierno (Lucr. III 1003-1010; Tib. I 3.79; Hor., Carm. III 11, II 14.8-20). 
Dánao, como ya hemos apuntado: Hipermestra es impía por desobedecer a su padre y piadosa por salvar a su marido; las Danaides son piadosas por obedecer a su padre e impías por matar a los maridos. Si tenemos que comparar a Eneas con alguna de ellas, al acabar con la vida de Turno el héroe actúa como las Danaides (Putnam 1994, p. 180), pues no muestra la clementia con la que se comporta Hipermestra.

De este modo, Eneas manifiesta una falta de clementia inspirándose en las Danaides. Ya antes de la Eneida, Horacio, al denominar a Hipermestra clemens y a las Danaides impiae en la Oda III 11, evidencia que, para el pensamiento romano, en la historia de las hijas de Dánao la virtud de la clementia tiene un papel relevante. Lo más interesante es que a Eneas en la epopeya virgiliana se le atribuyen tres de las cuatro virtudes augústeas, pero no la clementia (Estefanía 2017). Así, Ovidio toma a Hipermestra como un personaje que el lector de la Eneida ya consideraría antitético a Eneas, pues actúa de manera contraria a las Danaides, que a su vez sirven de modelo para el héroe; un personaje que, en definitiva, se rige según la clementia, la única virtud de la que carece Eneas ${ }^{16}$. Creemos que esa es la razón última por la que el autor elegiría a Hipermestra para deconstruir a Eneas: toma al personaje antitético y le dota de la virtud clave de Eneas, la pietas. De esta manera, Ovidio relaciona a Hipermestra con Eneas, y cuestiona si ambos pueden ser piadosos aunque se comporten de manera opuesta. Desde la perspectiva de la reescritura ovidiana, si Hipermestra perdona la vida a Linceo y por ello es piadosa, Eneas no puede ser piadoso si actúa de la manera opuesta a Hipermestra. Aquí se encuentra otro filón de deconstrucción con el que prácticamente llevar al absurdo la diferencia de virtudes según el género.

Pero aún hay una última relación que confirma la conexión entre Eneas e Hipermestra. Varios autores han señalado un vínculo intratextual entre el final de la Eneida y el final del libro VI. Cuando Eneas tiene que decidir si perdonar al Turno suplicante (Ille humilis supplexque, Aen. XII 930), el lector crítico recuerda el mandato que había dado Anquises a su hijo: parcere subiectis, et debellare superbos (Aen. VI 853) ${ }^{17}$. Lo que nos interesa es que el final de la

${ }_{16}$ Sobre la falta de clementia de Eneas en el final de la Eneida conviene citar a Galinsky 1988, pp. 323-324, quien defiende que desde el punto de vista de la moralidad romana de la época de Virgilio no habría ninguna ambigüedad en el comportamiento de Eneas: Turno era un criminal de guerra que no tenía que ser tratado con clementia.

17 Para una discusión más detallada, nos remitimos a Estefanía 2017, p. 43, n. 29. 
Eneida, cuando Eneas se comporta como una Danaide, remite al encuentro de Eneas con su padre, que es precisamente el pasaje que tiene una marcada relación intertextual con la Heroida XIV. Así, como hemos visto, los versos 45-50 de la Heroida en los que Hipermestra declara su pietas, remiten mediante alusiones verbales a un pasaje de la Eneida representante de pietas filial; pero a su vez, aprovechando la intratextualidad de la Eneida, estas alusiones verbales remiten al final de la epopeya, donde las Danaides influyen en las acciones no clementes de Eneas. De esta manera, el pasaje en el que Hipermestra decide perdonar la vida a su marido (Her. XIV 45-50) se conecta con el final de la Eneida en el que el héroe decide no perdonar a Turno.

\section{Conclusiones}

Consideramos que en este artículo hemos aportado argumentos lo suficientemente sólidos como para sostener la hipótesis de que Ovidio deconstruye a Eneas en las Heroidas. Las evidencias nos llevan a pensar que Ovidio establece entre Eneas e Hipermestra una relación irónica de contraste de la que se sirve para desmantelar valores culturales hegemónicos de los que hace propaganda la Eneida, como la virtud masculina de la pietas, y lo lleva a cabo situando en las Heroidas como valor central otro tipo de pietas, generalmente considerado femenino pero que Ovidio extiende también como modelo de comportamiento masculino. Recapitulemos las evidencias que se han proporcionado.

Primero, hemos analizado como prueba de la conexión entre Hipermestra y Eneas la relación intertextual entre Her. XIV 45-50 y Aen. 678 ss. Mediante las referencias verbales y la reescritura, Ovidio relaciona un pasaje en el que Eneas muestra piedad filial con uno de la Heroida en el que la heroína manifiesta su piedad conyugal. De esta manera utiliza el modelo de Eneas para crear una heroína pia que no había sido retratada como tal en la tradición, haciendo hincapié mediante la divergencia en que la pietas de Hipermestra es diferente de la de Eneas. Nuestra heroína, debido a su rol femenino, se decide por la piedad conyugal, y en ese sentido Ovidio utiliza las alusiones a la Eneida para establecer un paralelismo contrapuesto entre ambos personajes, que resultan paradigmáticos cada uno para cada género sociológico, y quizás yendo más allá, para su género literario.

Pero esta relación directa del tipo de virtud según el género queda también desmontada en las Heroidas. Ovidio sitúa la pietas conyugal, asociada a los valores femeninos, como central incluso para los hombres. Esto se ve claro 
en la Carta de Dido, donde se cuestiona e incluso se niega la pietas de Eneas, pues es representado como impius. A diferencia de lo que ocurre en la Enei$d a$, en el mundo de las Heroidas sería más importante que Eneas se rigiera por el tipo de pietas tradicionalmente femenina: solo así sería verdaderamente pius.

Asimismo, hemos defendido que la relación intratextual que conecta la Carta de Dido, donde Eneas es un personaje relevante, con la Carta de Hipermestra, donde el héroe no aparece (pia tura, Her. VII 25a; impia tura, Her. XIV 26), confirma que haya una intención consciente de Ovidio de fragmentar al héroe precisamente en la Heroida XIV, al mismo tiempo que elabora en ella un retrato indirecto de Eneas. En ambas cartas Ovidio pone de relieve las perspectivas marginales: la impiedad de Eneas y la piedad de Hipermestra.

Hemos apuntado también que la impiedad de Eneas en la Heroida VII proviene del libro IV de la Eneida, donde el héroe, desde la perspectiva de Dido, es representado por su carácter marginal de impío. Por tanto, se pueden observar dos caras del Eneas virgiliano, la piedad filial central y la impiedad conyugal marginal. Ovidio en la Heroida XIV crea una Hipermestra que también tiene dos caras, pero opuestas a las del héroe: la piedad conyugal frente a la impiedad filial. Lo importante es que, en la Heroida, Hipermestra es la protagonista y se impone su tipo de pietas conyugal.

Por último, hemos observado cómo en el final de la Eneida el héroe exhibe la misma falta de clementia que las Danaides y por tanto actúa de manera opuesta a Hipermestra. Esta conexión conceptual contrapuesta también se refleja textualmente, pues se puede advertir un vínculo intertextual entre Her. XIV 45-50 y el final de la Eneida, pasando por el pasaje del reencuentro padre e hijo en la Eneida como texto intermedio. En la misma línea de lo dicho anteriormente sobre la manera en que Ovidio intercambia los valores centrales y marginales de la pietas, podemos concluir, al analizar la conexión entre la decisión de la heroína y el final de la Eneida, que la relación que establece el autor entre Hipermestra y Eneas es bidireccional: no solo Eneas funciona como modelo (en oposición) de Hipermestra, sino que el comportamiento virtuoso de Hipermestra se impone sobre el de Eneas, lo cual ofrece una lectura según la cual Eneas no es tan heroico como aparenta, ahondando en la deconstrucción del personaje.

En definitiva, mediante la creación de una Hipermestra pia con el modelo (irónico en oposición) del pius Eneas, Ovidio realiza una fragmentación del héroe de la Eneida y sus valores prototípicos. El autor, en la Heroida, pone 
de relieve valores marginales que habían sido obviados por el discurso hegemónico: en este caso, destaca el valor femenino de la piedad conyugal frente a la piedad filial masculina, y lo hace sirviéndose de pistas intertextuales que apuntan al modelo que está deconstruyendo, de ahí la importancia capital del pasaje intertextual Her. XIV 45-50 y Aen. 678 ss.

Gracias a un complejo proceso intertextual, Ovidio sitúa a Eneas y su pietas filial en el margen, por un lado, y por otro lado posiciona la pietas conyugal en el centro como la única relevante, de tal manera que configura una Hipermestra que sustituye a Eneas como héroe piadoso, al mismo tiempo que desmantela la oposición masculino / femenino (centro / margen). En las Heroidas no parece haber lugar para el pius Aeneas.

\section{BiBLIOGRAFÍA}

Álvarez Morán, M. ${ }^{a}$ C. e Iglesias Montiel, R. M. ${ }^{a}$ (2004): «La Eneida homérica de Ovidio», en Amado, T. et al. (eds.), Iucundi acti labores. Estudios en Homenaje a Dulce Estefanía Álvarez, Santiago de Compostela, pp. 309-318.

Álvarez Morán, M. ${ }^{a}$ C. e Iglesias Montiel, R. M. ${ }^{a}$ (2009): «La odiseica Eneida de las Metamorfosis», $C F C(L) 29$ (1), pp. 5-23.

Battistella, C. (2011): «Genere e intertestualità in Ovidio: qualche riflessione su Met. 13.771-5; Her. 14.45-50; Ibis 153-8»<http://dictynna.revues.org/685> $(03 / 02 / 2020)$.

Blázquez Noya, A. (en prensa): «La pietas de Hipermestra en la Heroida 14: ¿una innovación ovidiana?», en Actas del XV Congreso de la SEEC, en proceso de preparación editorial.

Bonner, C. (1900): «The Danaid-Myth», TAPhA 31, pp. 27-36.

Casali, S. (1999): «Facta impia (Virgil, Aeneid 4.596-9)», CQ 49 (1), pp. 203-211.

Casali, S. (2003): «Impius Aeneas, impia Hypsipyle: narrazioni menzognere dall'Eneide alla Tebaide di Stazio», Scholia 12, pp. 60-68.

Ceccarelli, L. (2012): «La morte di Turno», MD 69, pp. 71-99.

Edgeworth, R. J. (2005): «The Silence of Vergil and the End of the Aeneid», Vergilius 51, pp. 3-11.

Ehwald, R. (1907): P. Ovidius Naso. Amores, Epistulae, Medicamina faciei femineae, Ars amatoria, Remedia amoris, Leipzig.

Estefanía, D. (2017): «Más sobre la muerte de Turno», $C F C(L) 37$ (1), pp. 33-50.

Estefanía, D. (2018): «La Eneida ovidiana. Una nueva interpretación», Emerita 86 (2), pp. 253-276.

Fernández Corte, J. C. (2018): «Las Metamorfosis de Ovidio: un (pre)texto para hablar de crítica literaria», en Cortés Tovar, R., González Marín, S. y Cantó Llorca, J. 
(eds.), Cum mens onus reponit... Artículos inéditos y selección de conferencias, Salamanca, pp. 199-216.

Fernández Corte, J. C. y Cantó Llorca, J. (2008): «Introducción», en Fernández Corte, J. C. y Cantó Llorca, J. (eds.), Publio Ovidio Nasón. Metamorfosis. Libros $I-V$, Madrid, pp. 7-204.

Fulkerson, L. (2005): The Ovidian Heroine as Author: Reading, Writing and Community in the "Heroides», Cambridge-Nueva York.

Galinsky, K. (1975): Ovid's Metamorphoses: An Introduction to the Basic Aspects, Berkeley.

Galinsky, K. (1988): «The Anger of Aeneas», AJPh 109 (3), pp. 321-348.

Greenough, J. B. (1900): Vergil: Bucolics, Aeneid, and Georgics, Boston.

Jacobson, H. (1974): Ovid's Heroides, Princeton.

Martínez Astorino, P. (2003-2004): «La Eneida en las Metamorfosis de Ovidio: interpretaciones y parámetros metodológicos para una relectura», Auster 8/9, pp. 97-109.

Martínez Astorino, P. (2017): La apoteosis en las Metamorfosis de Ovidio. Diseño estructural, mitologización y «lectura» en la representación de apoteosis y sus contextos, Bahía Blanca.

Moya del Baño, F. (1986): Ovidio. Heroidas, Madrid.

Palmer, A. (1898): P. Ovidi Nasonis. Heroides. With the Greek Translation of Planudes, Oxford.

Postgate, J. P. (1915): Tibulli aliorumque Carminum libri tres, Oxford.

Putnam, M. C. J. (1994): «Virgil's Danaid Ekphrasis», ICS 19, 171-189.

Ramírez de Verger Jaén, A. (2005): Publio Ovidio Nasón: obras completas, Madrid. Reeson, J. (2001): Ovid, Heroides 11, 13, and 14: A Commentary, Leiden. Shorey, P., y Laing, G. J. (1919): Horace, Odes and Epodes, Chicago.

Solodow, J. B. (1988): The World of Ovid's Metamorphoses, Chapel Hill-Londres.

Fecha de recepción de la primera versión del artículo: 04/02/2020

Fecha de aceptación: 25/06/2020

Fecha de recepción de la versión definitiva: 03/07/2020 